PO029

\title{
OBSERVING THE EFFECT OF CHROMATIC ADAPTATION ON COLOUR DISCRIMINATION UNDER DIFFERENT VIEWING CONDITIONS
}

\author{
Ágnes Urbin et al.
}

DOI 10.25039/x46.2019.PO029

from

CIE x046:2019

Proceedings

of the

29th CIE SESSION

Washington D.C., USA, June 14 - 22, 2019

(DOI 10.25039/x46.2019)

The paper has been presented at the 29th CIE Session, Washington D.C., USA, June 14-22, 2019. It has not been peer-reviewed by CIE.

(c) CIE 2019

All rights reserved. Unless otherwise specified, no part of this publication may be reproduced or utilized in any form or by any means, electronic or mechanical, including photocopying and microfilm, without permission in writing from CIE Central Bureau at the address below. Any mention of organizations or products does not imply endorsement by the CIE.

This paper is made available open access for individual use. However, in all other cases all rights are reserved unless explicit permission is sought from and given by the CIE.

CIE Central Bureau

Babenbergerstrasse 9

A-1010 Vienna

Austria

Tel.: +4317143187

e-mail: ciecb@cie.co.at

www.cie.co.at 


\title{
OBSERVING THE EFFECT OF CHROMATIC ADAPTATION ON COLOUR DISCRIMINATION UNDER DIFFERENT VIEWING CONDITIONS
}

\author{
Urbin, Á. Nagy, B.V. Wenzel, K. \\ Department of Mechatronics, Optics and Mechanical Engineering Informatics, Budapest \\ University of Technology and Economics, Budapest, HUNGARY
}

urbin@mogi.bme.hu

DOI 10.25039/x46.2019.PO029

\begin{abstract}
The objective of our study was to compare the effect of spectrally characterized chromatic adaptation on colour discrimination. Comparing just-noticeable stimuli of normal colour observers under two types of chromatic adaptation conditions with equal chromaticity and luminance but with different spectral content and field of view shows the importance of paying attention to illumination parameters that define the actual state of chromatic adaptation.
\end{abstract}

Keywords: Chromatic discrimination, Chromatic adaptation, Just-noticeable stimuli, Cambridge Colour Test (CCT)

\section{Introduction}

The experiment introduced in this paper is part of a research that aims to understand the limits and the mechanisms of chromatic adaptation based on observing chromatic discrimination abilities of normal colour observers under different states of chromatic adaptation.

\section{Methods}

In this paper the results of two experiments are presented. In one set of measurements with coloured filters in which 18 subjects participated and measurements with unfiltered eyes which were considered as reference. Detailed results of this measurements were shown at the CIE 2017 Midterm Meeting, Jeju. In the other set of measurements a spectrally tunable light booth provided the conditions defining chromatic adaptation and white light for reference measurements. The applied method of observing chromatic discrimination was measuring the just-noticeable stimuli.

Subjects of both experiments were between 20 and 22 years old, each of them normal colour observer. In both experiments subjects performed the trivector test of the Cambridge Colour Test (CCT). The measurements were approved by the United Ethical Review Committee for Research in Psychology (EPKEB, Hungary).

Measurements were executed in the Visual Systems Laboratory at the Department of Mechatronics, Optics and Mechanical Engineering Informatics, Faculty of Mechanical Engineering, Budapest University of Technology and Economics.

\subsection{Chromatic adaptation conditions}

In the study just-noticeable stimuli of normal colour observers measured with the trivector test of the Cambridge Colour Test were compared under two types of chromatic adaptation conditions.

In Experiment A subjects were wearing purple filters (further on noted as PF) or green filters (further on noted as GF) in a silicone frame. Reference measurements were executed with unaided eyes (further on NF).

In Experiment B subjects were watching the test through a spectrally adjustable light booth. The conditions were equal regarding chromaticity therefore in the light booth there was purple illumination (further on noted as PB), green illumination (further on noted as GB) and booth 
settings that provided the chromaticity of the neutral point of the display (further on noted as NB) as reference.

Measurements were executed in a darkened room. The spectral contents can be seen in Figure 1-2.

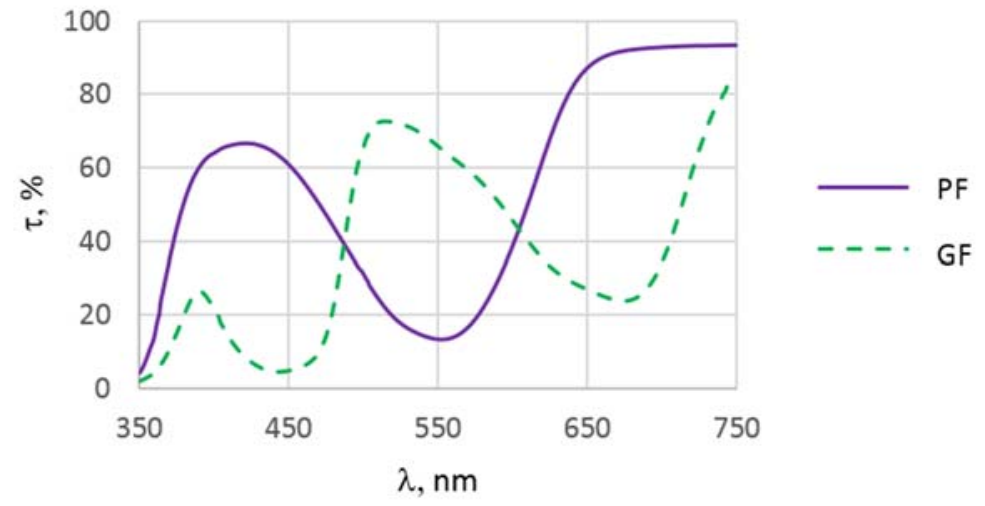

Figure 1 - Spectral transmission of the applied filters

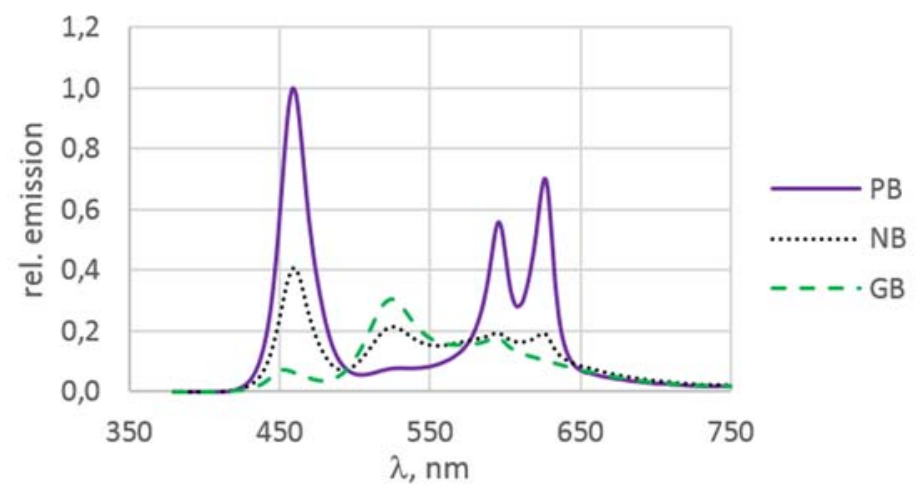

Figure 2 - Relative spectral emission of the applied light booth settings

Differences in the field of view should be also noticed. During Experiment $A$ only the display operated as light source and the filters affected the perceived amount of the spectral emission of the display itself.

During Experiment B the light booth provided a wider field of illumination and since the display was behind (therefore outside of) the light booth the spectral emission affected directly only the surrounding.

\subsection{Cambridge Colour Test}

Cambridge Colour Test is a display-based pseudoisochromatic test (Hasrod et al., 2015., Regan et al., 1994.) that provides the just-noticeable stimuli as result in defined directions from a reference point in the CIE 1976 UCS diagram (Schanda, 2007.). Subjects performed the trivector test in which three directions are defined towards the Protan, Deutan and Tritan confusion points. Reference points defined the chromaticity of the background while the chromaticity of the Landolt-C pattern changed on the three confusion lines in order to find the thresholds.

The reference points were shifted from the neutral point towards the above mentioned chromaticity of the filters and light booth settings in the CIE (1976) u'v' diagram. 
The test directions were set to the confusion axes towards the three confusion points. The range of luminance values both of the pseudoisochromatic plates and of the adjustable light booth were set considering the spectral transmission of the applied filters in order to reach equiluminance among the perceived stimuli.

\section{Results}

Analysis was executed regarding the following factors (and their levels): state of adaptation, condition of adaptation (filter or booth), analysed confusion line (Protan, Deutan, Tritan) and background chromaticity (distance from the neutral point towards the chromaticity point of the filter and in the opposite direction). Neutral point was labeled as zero and the ordinal numbers increased towards the arrows seen in Figure 3.

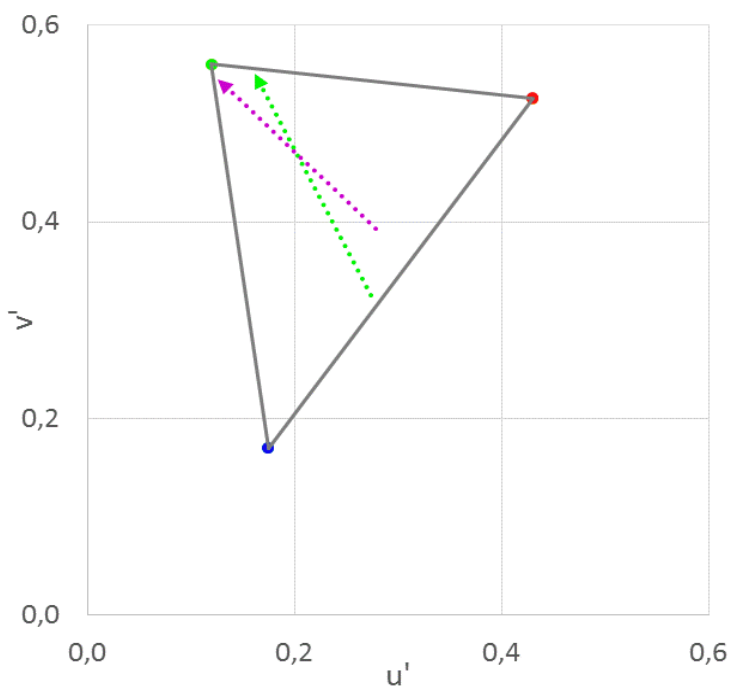

Figure 3 - The gamut of the display and the order of the reference points in the CIE (1976) u'v' diagram.

In order to find if chromatic adaptation affected colour discrimination the measured justnoticeable stimuli in both experiments were compared in each reference point.

The analysis showed that while adapting to the filters caused significant changes in chromatic discrimination depending on the background chromaticity compared to the results with the reference tests, adapting to the light distribution of the adjustable booth did not cause such change at all.

It is noticeable that even the result of the reference measurements showed differences: the neutral setting of the light booth (NB) indicated increase of just-noticeable stimuli compared to unaided (NF) conditions.

\section{Conclusions}

Since changing the coloured filters to the light booth affected both the spectral content and the luminance of the surrounding area further measurements are necessary to identify the clear source of the effects. However, our results show the importance of paying attention to details of viewing conditions such as field of view and spectral content of the illumination that defines the state of chromatic adaptation. 


\section{References}

COLOR AND VISION RESEARCH LABS, 1995. Colour \& Vision Research Laboratory and Database. at http://cvrl.org, 03.08.2017.

HASROd N., RUBin A., 2015. Colour vision: A review of the Cambridge Colour Test and other testing methods. Afr Vision Eye Health. 74(1), Art. \#23, 7 pages.

Regan, B. C., Reffin, J. P., Mollon, J. D., 1994. LuminanCe noise and the RaPid determination OF DISCRIMINATION ELLIPSES IN COLOUR DEFICIENCY. VISION RESEARCH, 34(10), PP. 12791299.

Schanda, J., 2007. Colorimetry - Understanding the CiE system. Hoboken: John Wiley \& SONS, INC.

URBIN, Á., NAGY, B.V., WenZEL, K., 2017. ChRomatiC DISCRIMINATION UNDER DIFFERENT STATES of Chromatic adaptation. Preceedings of the CIE 2017 Midterm Meeting, Jeju 